\title{
Mollusc Species Composition in Shell Bearing Sites At Kalamatiya, Southern Sri Lanka
}

\author{
T. Siriwardana \\ Department of Archaeology and Heritage Management, Rajarata University, Sri Lanka \\ thilanka.siriwardana@gmail.com
}

\begin{abstract}
This paper discusses the mollusc species composition as revealed from the mid-late holocene coastal shell bearing formations, which have not yet been widely considered. The primary goal of the research was to study shell middens located in association with shell beds at Kalamatiya in the southern Province. The range of species recorded from the site was employed as a criterion for define shell middens in the study. Excavation of a $1 \mathrm{~m}^{2}$ test unit was employed to gather data while soil samples from each layer were sieved to obtain micro remains. Total of 18 mollusc species recorded from the nine layers of a single site at Kalamatiya (Named site 01) are discussed here.
\end{abstract}

The most frequent species recorded was Meretrix sp. The layer six (shell midden) of site 01 displays a greater species diversity within the site in comparison to low numbers identified beneath layers. Layer six itself contained 12 species, i.e., Meretrix sp., Anadara sp., Donax cuneata, Saccostrea sp., Cerithedia cingulate, Acavus heamestoma, Aulopoma hofmeisteri, Beddoma trifasiatus, Papyridea soleniformis, Eunaticina sp., and two unidentified bivalve species (nacreous and calcareous). Therefore it seems that none of the middens in these formations is consisted of only one species. Total number of shells obtained from this layer was 2,393, whereas $96.5 \%$ is Meretrix sp. and other 11 species share 3.5\%. Species identified from other layers are Umbonium vestiarium, Oigospera polei, Lissachatina fullica, Tapes sulcarius, Purpura persica and Cryptonatica operculata. In general, the shell bearing sites tend to produce a good approximation of the range of species indicating that the pre historic inhabitants gathered whatever was available. These species are from a wide range of environments as littoral muddy sand, coastal sands, terrestrial and arboreal. Four of the species have one occurrence $(n=1)$ while another four species appear less than eight in number. Apart from building a taxonomical list, these data aid to study subsistence strategies of prehistoric communities and reconstruct their environment. Further these data can be used for palaeo-environmental reconstructions as well.

Keywords: Shells, Molluscs, Middens, Palaeo-environment 